\title{
Contemporary Theatre and the Experiential
}

In the context of the blurring of boundaries between club and theatre, game and theatre, and party and theatre, experiential spectatorship is spilling into the mainstream. This article starts from the recognition of the rapid rise of the experience economy as a turning point in consumer culture towards a specific appeal to the sensory body. The definition of experience in this analysis is key and a distinction is made between experience as it passes moment by moment, erlebnis, and experience as something that is cumulatively built up over time, erfahrung.

This paper asks, in a society defined by the crisis of experience, does this rise of the experiential in theatre simply reflect the reduction of experience to a series of consumable sensory moments or is there a mode of experience modelled through performance interaction which moves both beyond this established mode of experience and also beyond the notion of experience as cumulatively formed wisdom (erfahrung)? Drawing a parallel between established popular cultural practices of the body and those of the spectator in spectacular promenade performance, Fuerzabruta is used as an illustrative example of popular experiential performance and Hwang's The Road as an example of experiential performance in which a transformative aesthetic is made possible.

\section{Keywords: Contemporary theatre, Experiential, Promenade performance, Experience Economy, Spectatorship.}

Across the twentieth century there has been an enduring concern with redefining and reclaiming experience. The impoverishment, the crisis, the destruction of experience have been discussed at length by Benjamin, Adorno and Agamben. But what has been destroyed? What is left? What kind of experience do we place value on and why? For performance research, so concerned with the co-presence of the performer and spectator/participant, and the potential for transformative experience, the question of what experience means to us is central. Accordingly, this article is on the one hand a comparative analysis of two recent performances in the UK, which draws out the attributes of experiential theatre and considers the mode of experience in two very different performances. At the same time it is also a consideration of how experiential theatre is implicated in or reflects the deeper changes in modes of experience which define Western society in the $20^{\text {th }}$ and $21^{\text {st }}$ century.

The performances discussed are Fuerzabruta (2006), designed by director Diqui James in collaboration with Gaby Kerbel, and Eunhye Hwang's The Road (2009) presented as part of Marina Abramovic Presents (2009) at the Whitworth Gallery in Manchester. Fuerzabruta was a promenade performance combining fast paced performance with dancing, a DJ and the atmosphere of a club. It set narrative aside, placing emphasis on spectacle and multi-sensory perception, drawing the audience into interaction and participation, where touching the performers and parts of the set, moving around the space, and dancing generated their own kind of suspense. Hwang's The Road in contrast was a live durational piece of performance which built up a relationship very slowly with its audience, based on reciprocity of attention, and shared space and temporality. What these very different performances have in common is an emphasis on immersing the spectator into a liminal or liminoid space, an emphasis on engaging the spectator as an embodied mind and on generating a shared event through interaction and participation. These performances can both be described as experiential, however within that loose definition, each places emphasis on different modes of experience.

The primary approach to this discussion is through analysis of the performances as experienced by the spectator, and discussion of the nature of those experiences in relation to key discourses surrounding modes of experience in $20^{\text {th }}$ and $21^{\text {st }}$ century western society and current performance theory. An exploration into how we place value on these experiences, what they mean to us as spectators can only 
ever be partial and speculative because each of us experiences the work as one spectator with a particular perspective and set of expectations. It is with awareness of this limitation on the scope of analysis that this paper proceeds.

\section{What is Experience? What was Experience?}

Giorgio Agamben's “An Essay on the Destruction of Experience” in Infancy and History (1993) outlines in some detail the reasons why the experiences we pass through are no longer translatable into experience. While the distinction Walter Benjamin makes between erlebnis and erfahrung is not used in his text, it is clear from his writing, Agamben speaks of experience in this context as the durational accumulation of wisdom associated with generation to generation passing down of stories, proverbs and skills (erfahrung). He draws significantly on the work of Benjamin and extends his discussion of the impoverishment of experience through the horrors of the First World War suggesting that the destruction of experience is no longer specific to the catastrophe or crisis, but is evident in the passage of everyday life:

'[M]odern man's average day contains virtually nothing that can still be translated into experience. Neither reading the newspaper, with its abundance of news that is irretrievably remote from his life, nor sitting for minutes on end at the wheel of his car in a traffic jam. Neither the journey through the nether world of the subway, nor the demonstration that suddenly blocks the street. Neither the cloud of tear gas slowly dispersing between the buildings of the city centre, nor the rapid blasts of gunfire from who knows where...' (Agamben, 1993: 15-16)

This non-translatability of experience according to Agamben is accounted for in the displacing of experience into scientific experiment and verification, and according to Adorno (following Benjamin), into 'the selective, disconnected, interchangeable and ephemeral state of being informed, which as one can already observe, will promptly be cancelled by other information' (Adorno, 1993: 33).

If this is the case, and experience (erfahrung) is expropriated from the individual into scientific knowledge and information, firstly what we know as truth about the world becomes mediated by scientific institutions and the media. Secondly what we experience on a day to day basis, the events of a day or a life time are stripped of cumulative value. Their value is located in the instant of experiencing them and in the memory of that instant, but experience becomes an experience, something one has had rather than something to be carried with you: a shift from I have experience (erfahrung) to I had an experience (erlebnis).

In a mediatised, consumer society, we are thus faced with Debord's spectacle of competing images and truths where the ultimate version of truth is that we need to buy ourselves into a good experience to avoid the banality that Agamben describes. For Agamben the adventure is 'the final refuge of experience' for the modern world (1993: 33) and it is adventure, thrill or extreme that we turn to in an attempt to reinstate experience, believing if it is new, if it is different, if through the release of adrenaline it immerses in a different world, then it is the fullest kind of experience, perhaps even unique and authentic as the brochure inevitably suggests.

Accordingly, the consumption of experience has been the fastest growing economic sector for a long time, with both employment and GDP rising more than in any other section of the economy over the last forty years (Pine and Gilmore, 1999: 14 - 15). Joseph Pine and James Gilmore's The Experience Economy (1999) suggests this reflects a shift towards non-material commodities where experiences and sensations are sold as part of an 'experience economy'. This experience economy is a clearly distinguishable sector: the experience according to Gilmore and Pine is 'a fourth economic offering, as distinct from services as services are from goods'. If the customer pays for an experience, 'he pays to spend time enjoying a series of memorable events ' (Gilmore and Pine, 1999: 2). This perception of experience as something that can be marketed and sold, piecemeal to the consumer, is the clearest reflection of the shift towards experience as erlebnis. Correspondingly, according to Pine and Gilmore, 
experiences are judged by the sensation and memories they generate (1999: 12). They place emphasis on the desire for the unusual, the active over the passive, the engagement of the whole body and mind in the experience, all leading to immersion in the instant of the experience. The rise of the experience economy is thus a shift in consumer culture towards a specific appeal to the multisensory body, and the immediate in experience and a shift in our relationship with experience towards valuing each instant as we might value any other consumable object.

Powerful though this culture of consumption is, it is pessimistic to assume we are left trapped between Agamben's 'horror or lies' (1993: 18) and the escapism of Pine and Gilmore's experience economy. For if so, the lack of agency in terms of our relationship to both the world and ourselves, and the stripping back of the diachronic in experience in reducing experience to erlebnis, would lead to an unbearable and indeed impossible stasis. Thus, while recognising the impact of this shift toward erlebnis it is also important to recognise the potential to challenge our current condition and challenge the conceptual reduction of experience, in particular re-engaging the idea of transformation. Agamben, for example, seeks a way to liberate experience through alternative temporalities, critiquing the temporal conception of the instant in the continuum and attempting to engage history as a homely locus for memory and being. He states:

He who, in the epoche of pleasure, has remembered history as he would remember his original home, will bring this memory to everything, will exact this promise from each instant: he is the true revolutionary and the true seer, released from time not at the millennium but now. (1993: 115)

This raises challenges to the reduction of experience to erlebnis by reconceiving our relationship with time and history in such a way that we are located in and identified with our historical situation rather than separated from it as a series of objectified truth claims. Through the metaphor of the original home, a sense of the fondness, identity and connectedness with our history is generated. While Agamben does not make clear how it is possible to generate such a relationship or mode of remembering, it is a useful approach to thinking about our diachronic and synchronic engagement with our historical situation.

With the emphasis upon the sensory body in the construction of the consumable experience, however, it is also imperative to consider the emphasis on embodiment in contemporary experience and indeed to attempt to reconceptualise that in relation to embodied consciousness and transformation. It is for these reasons that a turn towards performance theory and the performative is taken to frame the analysis. Erika Fischer-Lichte's excellent analysis in The Transformative Power of Performance, draws on MerleauPonty and engages the notion of the embodied mind to generate a theory of 'radical presence' which allows for potential transformative experience (Fischer-Lichte, 2008: 99). This 'radical presence' according to Fischer-Lichte is enabled through the co-presence of performers and spectators in a liminoid space sharing a performance event. The performer's presence in which the 'opposition between body and mind/consciousness is erased enables the spectator to experience 'the performer and himself as embodied mind in a constant process of becoming - he perceives the circulating energy as transformative and vital energy' (Fischer-Lichte, 2008: 99). It is this radical presence which enables the transfiguration of the ordinary and transformation of the spectator, and thus enables a re-enchantment of the world for those spectators.

The analysis of the two performances below addresses this potential for the transfiguration of the ordinary through shared presence in experience theatre performance. However it first begins by addressing the experiential performance more generally and as a popular event with defined spectator/participant practices associated with clubbing and performance spectatorship. In both cases, a concern for the shared space and temporal experience of spectator and performer, heightened presence and embodiment are considered. Within the context of experiential performance practice, therefore, the question of whether the transformative potential is able to generate something more than immediate sensory experience of erlebnis is considered. What is it that makes one performance experience transformative and another just a great night out? 


\section{Fuerzabruta and popular experiential theatre}

The Fuerzabruta project was formed out of De La Guarda, after Diqui James, the artistic director, Gaby Kerbel, the musical composer and several of the production team decided they wanted to create new work after Villa Villa. Fuerzabruta generated an experience that combined theatre with dancing seamlessly enough that the Sunday afternoon, and Friday and Saturday night performances turned into a club night at the end of the show. The performance worked on multiple levels using the entire of the Roundhouse space to create an immersive environment. It made use of acrobatic skill, using performers on wires running on conveyor belts or running horizontally round the curtains above, smashing through cardboard boxes or desperately trying to put a cafe interior back together as conveyor belts whipped furniture away. The performance was presented in short sections, linked by the dynamics and atmosphere of the piece rather than by any kind of narrative.

The piece was fast paced and propelled the audience from one moment to another expecting them to spot the next section emerging from a curtain or from the ceiling and, when necessary, get out of the way. Each section of performance elicited a different level of spectator engagement and was visually very different. These fragments were held together by the music by Gaby Kerpel which accompanied the performance. Drawing on tribal electronica and world music it maintained the high level of energy generated at the beginning when the audience entered to a DJ's set. There are a number of key aspects of the performance that define the work as experiential which are examined below: the shift from narrative based character identification to direct emotional and embodied engagement with the performance world and performers; the consequent shift away from narrative suspense; and the participation and interaction of the audience.

Narrative in Fuerzabruta was very much set aside as the piece presented a sequence of unrelated installation performances which appeared in different parts of the space. While the first image, a man running desperately on a conveyor belt smashing his way through walls, has been subject to some interpretation by reviewers ${ }^{1}$, the Fuerzabruta website claims, that 'Fuerzabruta doesn't have a purpose. [...] It doesn't exist in the work, the concept of significance or representation' (Fuerzabruta Website). Indeed while at first some of the images seemed highly symbolic and perhaps to speak to a common cultural experience of struggle of some kind, this interpretive engagement faded as the piece progressed, partly because of the dissociation of the sequence of images and partly because of the excess of stimulation through spectacle, music, dancing and shouting. As the Fuerzabruta group state on their website, they 'want to break intellectual submission of the language... the speed of the stimuli the spectator receives, supersedes the intellectual reaction' (Fuerzabruta Website).

As the desire to construct a narrative faded, awareness of one's own embodiment and a connection with the performers developed. There was a strong bodily connection and identification between the spectator, the performers and the other members of the audience. Thus, immersion into the experience is partly physical and emotional, but also it is linked to 'recognition' (Frank, 1991: 87). What is meant here is not narrative recognition as might be associated with the image of the running man in the opening scene, but is a recognition of a bodily state or experience through the 'communicative body' (Frank, 1991: 89). 'What is shared is one body's sense of another's experience, primarily its vulnerability and suffering, but also its joy and creativity' (Frank, 1991: 89).

In Fuerzabruta, because identification is with the performers rather than characters, the primary identificatory engagement is through this bodily recognition, engaging with the joy and creativity or

\footnotetext{
${ }^{1}$ Chris Moss suggests it is 'Central to the show'. He describes 'a tall, wiry young man, suspended from the roof, [...] dressed in a shirt and tie, like an anonymous office worker, trying to make headway in the face of all the challenges life can throw at him' (Moss, 2006: npg).
} 
indeed the aggressive destructiveness of each moment as it is performed. Towards the end of the performance, for example, above the audience, a screen holding a few inches of water descended into view, reaching across the entire space. The performers threw themselves on to the screen over and over, smashing themselves flat bodied on to the surface. They danced in the water, first using their bodies as the moving material of the dance then manipulating the splashes and currents of the water to make it dance around them. The 'recognition' here was not an interpretation of what this might symbolise, rather an engagement with what was happening in that moment, seeing the bodies of performers dancing and realising the dance had shifted. Rather than being located solely in the performers' bodies the visual effect gradually shifted into the movement of the water so that the water danced with the performers. What is interesting here is the physical appreciation and recognition of the performers' bodily playfulness and visceral experience.

This immersion of the audience into the creative process is generated through the presentation of playfulness and celebration of playful physical creation. Despite not directly being a part of that process themselves, spectators can feel a part of this in celebrating and connecting through touch and eye contact with the performers.

This section of the performance also demonstrates how a build up of suspense can be made possible without narrative; through participation and the desire for contact either physically or through the exchange of the gaze. As the screen was lowered closer and closer to the audience below, the increasing proximity increased excitement and expectation until the screens were just above the spectators' heads: close enough to run your palms over the bodies of the performers as they shot across the screen. This relationship between suspense and proximity was hugely significant in the performance as a whole because the structure of the piece is such that the audience is teased by the proximity of various elements of the performance at different times: water sprinklers, or the chance to mingle with the performers as they smash boxes over people's heads. The audience never had enough contact as each section of the performance appeared in a different part of the space, the opportunity for contact or touch appeared and disappeared throughout.

This tension only emerged because of the physical participation of dancing and the emotional engagement associated with both aggressive destruction and celebration. Both this atmosphere of celebration and the level of audience interaction with the piece increased over the course of the performance. By the end, the performers present a manic but choreographed dance to hybrid world folk tribal dance music and as they do so, they rip down the walls of the structure they are in, leaving just the support beams standing. The wildness of the dance and destruction are celebratory and spill into the audience. At the end of this section, spectators smashed their heads through boxes and danced with the performers as they mingled with the audience. The Fuerzabruta group tell us 'The public doesn't take part, they form part. Injured. Celebrating' (Fuerzabruta website) and for the willing participant that contradictory intensity is indeed possible.

To make possible this level of intensity, immersion and desire to participate, the sense of a shared liminal space is absolutely central. Within this, it is the club-like aspects of the piece in particular which immerse the spectator in a full bodily experience, enhancing the sense of recognition between the spectators and performers by engaging the body actively dancing to music in a celebratory and joyful way alongside the playful creative force of the performers' bodies, but also creating a communal experience amongst the audience.

From the beginning, the performance provided a passage into what Turner describes as a 'liminoid' state (Turner, 1982:24). The act of entering a different space and the second separation when the curtains are drawn around the space were enhanced by a shift in the experience of time and embodiment as the rhythms of the day were set aside and replaced by those associated with dancing. As in a club environment, embodiment shifted outside the normal social habitus by crossing into a liminoid space and time, triggered by the combination of the very intense musical experience, a separated space and the sense of shared experience and connection. For the spectator at Fuerzabruta, the build up to the final scene 
allowed absolute immersion into the moment of dancing where the subjectivity is immersed into the body and communal experience. Emerging from an afternoon performance drenched in water, covered in debris and wanting to dance all night, was hugely disorientating. The expectation that it would be night was overwhelming. This performance was a powerful embodied experience and undeniably replicated the immersion and the celebratory sense of community amongst its audience that is associated with clubbing, generating an intersubjective exchange of energy and emotion.

However, whether Fuerzabruta moves beyond the experience of the moment, the consumable fragmented experience of the experience economy is debateable. The irony is of course that twenty years on from the emergence of the rave scene, clubbing is big business, as much a part of the experience economy as extreme sports. Subcultural embodiments that could once be theorised as disruption of habitus now form part of the conventional work/play dichotomy that defines everyday embodiment.

Before attempting to decide if this was any more than a great night out, the analysis below of The Road by Eunhye Hwang provides an interesting counterpoint to this experience.

\section{Hwang's The Road: Quiet Intimacy}

Hwang's The Road was a live performance presented in Marina Abramovic Presents at the Whitworth Gallery in 2009. This meant that this particular experience of her work was framed by Marina Abramovic's own introduction to the afternoon, entitled The Drill and the spectators were asked to guarantee they would stay the full 3 hours to see the work in the gallery. On entering the gallery, spectators were given lab coats and taken to a room in which Abramovic set everyone out in rows on fold-up chairs. The purpose of the initial session was to frame the work presented but also to prepare the spectators for the afternoon; to transform spectators into participants.

Perhaps even more so than in Fuerzabruta, there was a well defined process of separation from everyday life. This involved a series of guided exercises: drinking water slowly and mindfully; holding serious, vulnerable eye contact with a series of strangers and walking slowly and mindfully through the space. This process functioned as an opening up of awareness of the spectators' bodies, their relationship to space and each other: a passage from an ordinary state of being into a heightened state. Mirroring, but working in exact opposition to the opening of Fuerzabruta, spectators were slowed down and made hyperaware of their bodies in shared liminoid space: a space where intimacy, vulnerability and stillness were allowed. This intimacy and willingness to share an openness and vulnerability with the performers was integral to Hwang's The Road.

The room in which Hwang performed was large enough that spectators had an expanse to sit, or stand in, giving them the freedom to distance themselves from the work or move in closer. There was a refrigerator, and a table with a radio on it but the room was otherwise bare. Spectators could come and go as they pleased, and the sequence described below took approximately an hour and a half.

On entering the room there was a young woman lying on the floor, well dressed and making small waves of movement with her body. There was a sound like waves and it appeared at first as if the sound accompanied the movement. Over time these waves of movement and sounds shifted, increased, decreased in pace or intensity and gradually it became clear that by holding the speakers between her legs and under her arms, Hwang was controlling the sound with her body. She gradually stood up, and very slowly sought out eye contact. She began moving closer very slowly and gently, then moving away again, and over time, she built up a relationship in which the spectators felt comfortable holding her gaze and began to feel a connection to her. The build up of proximity and trust through her movement followed in its dynamics, the flow and ebb of the waves which begun the performance.

After this gradual process of building trust and making contact over time, eventually Hwang made contact very slowly and carefully with a willing spectator. She hugged someone. This was very clearly a mutual hug and several members of the audience including the woman she hugged cried. After some time when 
the moment had passed, Hwang took jelly from the fridge and the spectator/participants played at wobbling jelly and joined her in doing little playful dances with the jelly, before eating a spoonful each.

Why did so many people cry? According to students and colleagues this was not a one off response although it did not occur in every instance. As in Fuerzabruta, the slow build up of contact and the fact that this contact or intimacy was withheld meant that it became something desired by spectators. However, the response here was very different. As in Fuerzabruta the connection or identification was with the performer as a persona and other audience members, not to a fictional character or characters and this is significant because the emotion felt was not displaced on to a character, whose perspective the spectator took on. In this work, the emotion was experienced directly. This meant that spectators felt ownership of the celebration and sense of community in Fuerzabruta and that moment of intimacy in The Road, though the experiences were shaped through a relationship with performed personas.

In The Road the attributes of experiential theatre are all as relevant as in Fuerzabruta. A clearly defined liminoid space and temporal zone is constructed around the work, the spectator is engaged very much as a participatory embodied mind, hyperaware of a shared space and event. However, where Fuerzabruta sped up interaction to the point of frenzy, preventing the spectator from engaging intellectually or interpreting what was happening, Abramovic's introduction and Hwang's The Road slowed us down. Where Fuerzabruta deafened us, The Road was quiet and intimate. In addition, in The Road the level of autonomy and choice the spectator had was far greater than in Fuerzabruta. In The Road, the spectator could move anywhere, leave, come back, avoid any contact or participation at all or stand right in front of the performer.

While Hwang initiated and shaped the dynamics and relationships in the performance, each spectator shaped his or her side of that relationship. Hwang engaged each spectator in an exchange of gaze or trust and, for some, of touch. The choice to leave, to sit at the edge of the room or at a safe distance means the exchange of gaze as a mutual choice or the exchange of physical affection is much more powerful. These conditions led to a deeper and more intimate connection through the piece than was possible in Fuerzabruta. It enabled what Fischer-Lichte describes as 'radical concept of presence': by creating this liminoid temporality in a shared space the experience of shared presence heightened. The ordinary state of embodied consciousness and the ordinary state of shared space and time were transfigured to the extent that people were overwhelmed by the intimacy of sharing contact and sharing presence. It is here there is a significant difference in the nature of the relationship between performer and spectator in the two pieces. In Fuerzabruta, the speed of the stimuli disrupts an intellectual response almost completely: the body is given primacy over the mind. In The Road, the sense of our bodies and minds sharing a space and making a connection across that space is heightened. Presence here is an intersubjective experience, an opening up which allows a connection between individuals which has transformative potential. The point at which Hwang hugged someone became a release for several spectators because the heightening of presence, vulnerability, trust and awareness of the potential for a connection or moment of intimacy mirrored a lack of that kind of openness and shared presence in ordinary experience.

\section{Conclusions}

Experiential theatre integrates interaction and often embodied participation into spectator engagements; it involves direct engagement with the world of the performance, rather than solely identificatory engagements through character perspective and thus generates an experience of performance as event. It generates a liminoid space which sits on the boundary between the real and the imaginary. Both the performances above are powerful experiential performance events; however, their modes of engagement are fundamentally different due to the opposing shifts in temporal experience. The potential for transformative bodily experience theorised in relation to the rave culture of the late eighties is no longer applicable in the same way in the context of the $21^{\text {st }}$ century experience economy's hold on clubbing and the integration of its associated habitus into the mainstream. The potential for transformative experience 
is in this instance located in the potential for heightened co-presence and intimacy.

The poet Alistair McIntosh suggests in his book Soil and Soul that 'cultural healing entails coming alive to community with one another, with the place where we live, and with soul' (2004: 4) and to do that 'We must face the reality of a brokenness of heart that is both personal and of the world' (2004: 2). While there is a sense in which both of these performances seek to enable this kind of moment of coming alive to community with one another, Fuerzabruta, sets up this communal celebration on the firm base of an established set of bodily practices and associations with clubbing. The energy of that work generates a sense of invulnerability through its wild destructive energy, chaos and dancing. The work is transformative only in the moments the spectator is in it, creating a liminoid space which doubles as a wild party. You leave wet, dazed and happy after a great night out.

The combination of Abramovic's introductory meditations and Hwang's The Road in contrast was able to leave the spectator altered for some significant time. Within the work itself the spectator is able to bring him or herself into a state of heightened presence where that presence is a shared, intimate and vulnerable one. If we are not, as McIntosh suggests, broken hearted on a personal and societal level, it is impossible to understand the emotional response to building up trust and intimacy in Hwang's performance. To unpick the idea of the original home that Agamben refers to, there is a correlation between this notion of a place of origin, identity and comfort and the experience of intimacy described in relation to The Road. The original home as a memory is associated with shared identity and co-presence and the reluctance or fear of opening ourselves to a shared experience of the world that McIntosh identifies sits in opposition to that.

What this analysis opens up for continuing thought is this correlation between shared, heighted and vulnerable intimacy and the shared identity of the original home. While the reincarnation of our relationship to the present world and our history based on the memory of original home may not be possible, the use of this model as a basis for thinking about transformative experience is illuminating. The mode of experience that appears to have been destroyed in Agamben's work is based on inter-generational relationships and an accumulation of wisdom in relation to the world and is appropriate to a theory of coherent subjectivity now obsolete. The notion of the transformative outlined here posits a shifting and fluid subjectivity and allows experience to become more than simply erlebnis, more than an adventure to be consumed. Experience is not solely a fragment no longer integrated into a wider continuum of cumulative experience. The transformative frames the experiences we pass through on a daily basis with a potentiality that challenges their reduction to erlebnis. 


\section{References}

Abramovic, Marina (2009) The Drill. Live performance at The Whitworth Gallery, Manchester.

Adorno, Theodor (1993) 'Theory of Pseudo-culture 1959.' Deborah Cook, trans. Telos 95.

Agamben, Giorgio (1993) Infancy and history: on the Destruction of Experience. Liz Heron (trans.) London: Verso.

Benjamin, Walter (1933) Experience and Poverty. In Walter Benjamin (1999) Walter Benjamin: Selected Writings, Volume 2: 1927-1934. Michael Jennings et al. (eds) Cambridge, Mass.: Belknap Press of Harvard University Press, 731 - 7.

Benjamin, Walter (1929) The Return of the Flaneur. In Walter Benjamin (1999) Walter Benjamin: Selected Writings, Volume 2: 1927-1934. Michael Jennings et al. (eds) Cambridge, Mass.: Belknap Press of Harvard University Press, 262 - 267.

Debord, Guy (1983) The Society of the Spectacle. The Black \& Red Project (trans). Detroit: Black and Red Press.

Fischer-Lichte Erika (2008) The Transformative Power of Performance: a New Aesthetics. Saskia Iris Jain (trans) Oxon: Routledge.

Frank, Arthur (1991) For a Sociology of the Body: an Analytical Review. In: Mike Featherstone (ed.) The Body, Social Process and Cultural Theory. London: Sage Publications.

Fuerzabruta (2006) Fuerzabruta. Live performance at The Roundhouse, London.

Fuerzabruta website, www.fuerzabruta.net, accessed 16/07/2007.

Gilmore, James H. and Joseph Pine (1999) The Experience Economy: Work is Theatre and every Business a Stage. Boston, MA: Harvard Business School Press.

Hwang, Eunhye (2009) The Road. Live performance at the Whitworth Gallery, Manchester.

McIntosh, Alistair (2004) Soil and Soul: People versus Corporate Power. London: Aurum Press.

Moss, Chris (2006) Fantasy Factory. The Daily Telegraph [online]

www.telegraph.co.uk/culture/theatre/3652371/Fantasy-factory.html. Accessed 16/09/2010.

Turner, Victor (1982) From Ritual to Theatre: the Human Seriousness of Play. New York: PAJ Publications. 